\title{
Role of Androgen Receptor in Prostate Cancer: A Review
}

\author{
Kazutoshi Fujita®, Norio Nonomura ${ }^{\circledR}$ \\ Department of Urology, Osaka University Graduate School of Medicine, Suita, Japan
}

\begin{abstract}
Androgen receptor (AR) is a steroid receptor transcriptional factor for testosterone and dihydrotestosterone consisting of four main domains, the N-terminal domain, DNA-binding domain, hinge region, and ligand-binding domain. AR plays pivotal roles in prostate cancer, especially castration-resistant prostate cancer (CRPC). Androgen deprivation therapy can suppress hormone-naïve prostate cancer, but prostate cancer changes AR and adapts to survive under castration levels of androgen. These mechanisms include AR point mutations, AR overexpression, changes of androgen biosynthesis, constitutively active AR splice variants without ligand binding, and changes of androgen cofactors. Studies of AR in CRPC revealed that AR was still active in CRPC, and it remains as a potential target to treat CRPC. Enzalutamide is a second-generation antiandrogen effective in patients with CRPC before and after taxane-based chemotherapy. However, CRPC is still incurable and can develop drug resistance. Understanding the mechanisms of this resistance can enable new-generation therapies for CRPC. Several promising new AR-targeted therapies have been developed. Apalutamide is a new Food and Drug Administration-approved androgen agonist binding to the ligand-binding domain, and clinical trials of other new AR-targeted agents binding to the ligand-binding domain or $\mathrm{N}$-terminal domain are underway. This review focuses on the functions of AR in prostate cancer and the development of CRPC and promising new agents against CRPC.
\end{abstract}

Keywords: Androgen receptor; Apalutamide; AR-V7; Castration resistant; Prostate cancer; Testosterone

This is an Open Access article distributed under the terms of the Creative Commons Attribution Non-Commercial License (http://creativecommons.org/licenses/by-nc/4.0) which permits unrestricted non-commercial use, distribution, and reproduction in any medium, provided the original work is properly cited.

\section{INTRODUCTION}

The incidence rate of prostate cancer is increasing and is highest in Japan and the United States. In the 1940s, Charles Huggins found that patients with metastatic prostate cancer could be treated by androgenablation therapy, which was the beginning of prostate cancer therapy [1]. Currently, a new generation of antiandrogen drugs are available, and further new drugs are under clinical study to test their effectiveness in patients with castration-resistant prostate cancer
(CRPC). Androgen exerts its various functions by binding to androgen receptor (AR). Chang et al [2] first cloned human and rat AR cDNAs in 1988. This article reviews $\mathrm{AR}$ in regard to prostate cancer.

\section{ANDROGEN RECEPTOR STRUCTURE AND FUNCTION}

$\mathrm{AR}$ is a member of the nuclear receptor superfamily and has a similar structure to estrogen receptor, progesterone receptor, glucocorticoid receptor, and

Received: May 16, 2018 Revised: Jun 18, 2018 Accepted: Jun 18, 2018 Published online Sep 10, 2018

Correspondence to: Kazutoshi Fujita iD https://orcid.org/0000-0002-6774-7497

Department of Urology, Osaka University Graduate School of Medicine, 2-2 Yamadaoka, Suita, Osaka 565-0871, Japan.

Tel: +81-6-6879-3531, Fax: +81-6-6879-3539, E-mail: kazufujita2@gmail.com 
thyroid hormone receptor. The AR gene is located on chromosome X (Xq11-12) and consist of 8 exons coding about $11 \mathrm{kDa}$ protein. $\mathrm{AR}$ has four regions: from the $\mathrm{N}$-terminal, an $\mathrm{NH} 2$ terminal transactivation domain (NTD) encoded by exon 1, a DNA-binding domain (DBD) encoded by exons $2-3$, a hinge region encoded by exon 4 , and a ligand binding domain (LBD) encoded by exons 5-6 (Fig. 1A). The NTD has glutamine repeats (CAG repeats), and these glutamine repeats vary (most men have 19-25 repeats), which results in the variation of all amino acids in AR. AR has approximately 919 amino acids, which have been registered at the AR gene mutation database [3]. Shorter glutamine repeats are associated with high transcriptional activity of AR [4]. Men with shorter glutamine repeats have a higher risk of prostate cancer [5]. In contrast, patients with Kennedy disease have long CAG repeats $(>40)$, which results in low AR-transcriptional activity with gynecomastia, erectile dysfunction, testicular atrophy, and muscular atrophy [6]. Testosterone and dihydrotestosterone (DHT) bind to the LBD, followed by the conformational change of AR. After ligand binding in the cytoplasm, AR translocates into the nucleolus, forms a dimer, and binds to the androgen-response element of the promoter and the enhancer of targeted genes through the zinc-finger of the DBD. The NTD includes the transcriptional regulatory region, activation function-1 (AF1), and the LBD includes activation function-2 (AF-2) [7]. Upon DNA binding, the AR dimer forms a complex with coactivator and coregulatory proteins at the AF-1 and AF-2 regions. These proteins include SRC1, SRC2, SRC3, p300/CBP, and AEA54, among many others. AR regulates the gene expressions with diverse functions located downstream of the androgen-response element, including secreted proteins (KLK3, KLK2), fusion genes (TMPRSS2-ERG), growth stimulators (IGF1R, APP), PI3K modulation (FKBP5), transcription factors (NKX3.1, FOXP1), metabolic enzyme (CAMKK2), cell cycle regulators (UBE2C, TACC2), and glucuronidation (UGT1A1) [8].

AR also represses transcription. The formation of an activation complex involves AR, coactivators, and RNA polymerase II recruitment to both the enhancer and promoter, whereas the formation of a repression complex involves factors bound only at the promoter and not at the enhancer [9].

Androgens are synthesized in the testis and adrenal glands. Testosterone is synthesized by Leydig cells in the testis, and androstenedione and dehydroepiandrosterone (DHEA) are synthesized in the adrenal glands. Most testosterone in the serum binds to sex hormone binding globulin, whereas the remaining $1 \%$ to $2 \%$ exists as free testosterone, which is converted into DHT by 5 -alpha-reductase in the prostate cells. DHT has a high binding affinity to AR. Adrenal androgen is converted to testosterone by 17-beta-hydroxysteroid dehydrogenase in the cytoplasm of prostate cells. In normal prostate, immunohistochemical analysis showed strong staining for AR in luminal cells, fibromuscular stromal cells, and endothelial cells but weak staining in basal cells [10]. In normal prostate, epithelial AR acts to supply secretory proteins to the prostate gland, such as prostate-specific antigen (PSA). Stromal AR plays roles in prostate growth. In mice, selective knock-out

A

Located on $\mathrm{X}$ chromosome, q11-12

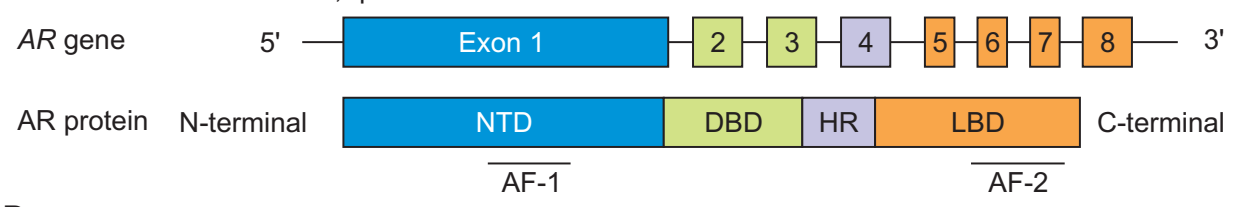

B

AR variant

AR-V3

AR-V4

AR-V5

AR-V7

AR-V567es
NTD

NTD

DBD $\quad$ CE4

NTD

\begin{tabular}{l|l} 
DBD & CE4 \\
\hline
\end{tabular}

\begin{tabular}{|c|c|c|c|}
\hline NTD & DBD & CE4 & \\
\hline NTD & DBD & CE4 & \\
\hline NTD & DBD & CE2 & \\
\hline NTD & DBD & CE3 & \\
\hline NTD & DBD & HR & LBD \\
\hline
\end{tabular}

Fig. 1. Structure of androgen receptor (AR). (A) Full-length AR is composed of 8 exons. (B) AR splice variants are truncated at DNA-binding domain (DBD) or ligand-binding domain (LBD). NTD: Nterminal domain, HR: hinge region, AF1: activation function-1, AF-2: activation function-2, CE: cryptic exon. 
of stromal AR (fibroblasts and smooth muscle cells) inhibited normal development of the prostate [11]. In prostate cancer, the actions of AR are synthesis of PSA, regulation of lipid metabolism, promotion of growth, and several other functions [12]. Gene fusions between the transmembrane protease serine 2 gene (TMPRSS2) and E twenty-six (ETS) in prostate cancer cells were first discovered in 2005 [13]. The most frequent gene in the ETS gene family fusing with TMPRSS2 was the ERG gene (present in approximately $85 \%$ of all ETS fusion-positive samples). The prevalence of TMPRSS2ERG was $30 \%$ to $50 \%$ in patients with localized prostate cancer. Stromal AR plays a Transcription of TMPRSS2 gene was regulated by AR. Loss of stromal AR also suppressed the development of prostatic intraepithelial neoplasia by modulating pro-inflammatory cytokines/ chemokines in a mouse model of prostate cancer [11].

\section{CHANGES OF ANDROGEN RECEPTOR IN PROSTATE CANCER}

Androgen deprivation therapy can suppress most prostate cancers, but some high-risk prostate cancers gradually progress to CRPC, which can grow under castrated levels of androgen. AR is the most frequently aberrant gene in metastatic CRPC (62.7\%) [14]. Several mechanisms underlie the development of CRPC.

\section{Point mutations in androgen receptor}

Point mutations in the AR gene were found in $15 \%$ to $30 \%$ of CRPC patients [15,16], most frequently in the LBD, followed by the NTD [3]. These point mutations can activate AR by losing the specificity of the agonist. For example, the point mutation of T878A results in the loss of specificity for the agonist. Progesterone, estrogen, flutamide, bicalutamide, and enzalutamide can activate $\mathrm{AR}$ with the T878A point mutation [1719]. T878A was the first identified point mutation of AR driven by flutamide, but T878A also exerts resistance to second-generation AR agonists [20]. The F876L point mutation changes the LBD domain and confers resistance to enzalutamide [21,22]. T878A or L702H mutations were found in the plasma of $13 \%$ of CRPC patients with abiraterone resistance [23]. These mutations can be detected in plasma DNA and may help physicians in choosing the appropriate drugs for CRPC patients [24]. AR L701H and AR L701H/T877A are somewhat less sensitive to androgens but are highly responsive to the glucocorticoids cortisol and cortisone [25].

\section{Androgen receptor amplification}

AR gene amplification was found in $30 \%$ to $50 \%$ of CRPC patients, resulting in the overexpression of AR $[26,27]$. Even under androgen deprivation therapy, low levels of androgen still exist. AR overexpression enables prostate cancer to progress to castration levels of androgen. Prostate cancer cells with AR amplification can survive under androgen deprivation therapy, progressing to CRPC. AR amplification was more common in patients resistant to enzalutamide than to abiraterone [20].

\section{Changes of androgen biosynthesis}

During androgen deprivation therapy, low levels of androgen are found in the serum. Cytochrome P450 enzymes CYP11A1 and CYP17A1 in the adrenal gland synthesize DHEA and androstenedione. Normal prostate cells can convert these weak adrenal androgens into testosterone and DHT. CRPC overexpresses these converting enzymes, such as the aldo-keto reductase family 1 member C3 (AKR1C3) [27]. CRPC also expresses a gain-of-stability mutation leading to a gain-

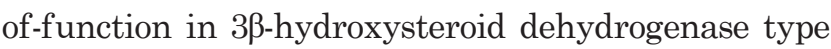
1 (HSD3ß1). HSD3 31 catalyzes a rate-limiting step for DHT synthesis from the adrenal DHEA. CRPC expressing mutated HSD3 $\beta 1$ can produce enough DHT to activate AR [28]. Abiraterone, a CYP17A1 inhibitor, can stop this supply from the adrenal glands. However, CRPC can also synthesize significant levels of androgens de novo from cholesterol and become independent of the circulating adrenal androgens. Metastatic prostate cancers obtained by warm autopsies express transcripts encoding androgen-synthesizing enzymes (HSD381, CYP17A1, and AKR1C3) and maintain intratumoral androgens at concentrations capable of activating $\mathrm{AR}$ target genes and maintaining tumor cell survival [29]. Intratumoral expression of CYP17A1 was markedly increased in tumor biopsies from CRPC patients after abiraterone [30]. CRPC resistance to abiraterone may still remain androgen dependent.

\section{Changes in androgen receptor receptor cofactor in prostate cancer}

$\mathrm{AR}$ coactivator interacts directly with $\mathrm{AR}$ and stimulates transcriptional activity of $\mathrm{AR}$ function. 
The formation of AR coactivator complexes enhances the opening of the chromatin structure at AR-binding sites, which results in the recruitment of transcriptional machinery to target the genes. The SRC family is a p160 group consisting of three evolutionary conserved coregulators of transcription: SRC-1 (NCOA [nuclear receptor coactivator]-1), SRC-2 (NCOA-2), and SRC-3 (NCOA-3) [31].

SRC-1 expression is associated with prostate cancer aggressiveness, and suppression of SRC-1 expression reduced growth and altered $\mathrm{AR}$ target gene regulation in prostate cancer cells [32]. However, in a murine prostate cancer model, the role of SRC-1 is nonessential for carcinogenesis and different from the essential contribution of SRC-3, which is required for prostate cancer progression and metastasis in mice [33].

AR coactivator NCOA2, or SRC-2, is amplified in primary and metastatic prostate cancer [34]. Androgen deprivation induces NCOA2, which activates PI3K signaling and promotes prostate cancer metastasis and the development of CRPC [35]. NCOA2 stimulates reductive carboxylation of alpha-ketoglutarate to promote lipogenesis and the reprograming of glutamine metabolism. The SRC-2-driven metabolic signature is strongly increased in metastatic prostate cancers. NCOA2-dependent transcriptional reprogramming may play a role in resetting the tumor metabolic pathways to support uncontrolled growth and survival [36].

SRC-3 expression is increased in advanced prostate cancer. It is elevated in CRPC and negatively correlates with PTEN expression and recurrence-free survival of prostate cancer patients. SRC-3 is necessary for the development of CRPC by enhancing Akt activity and S6K1 expression [33]. Normal SPOP (speckle-type POZ protein) plays important roles in tumor suppression in prostate cancer by promoting SRC-3 turnover by ubiquitination and suppressing AR transcriptional activity. The prostate cancer-associated SPOP mutant cannot interact with SRC-3 protein or promote its ubiquitination [37]. CBP (cyclic adenosine monophosphate response element binding protein binding protein) and p300 are known coactivators of $\mathrm{AR}$ and play an oncogenic role in prostate cancer. Androgen deprivations caused the upregulation of $\mathrm{CBP} / \mathrm{p} 300$ proteins in prostate cancers [38]. Inhibition of the $\mathrm{CBP} / \mathrm{p} 300$ bromodomain blocked AR activity at the chromatin level, resulting in the suppression of proliferative gene expressions and tumor growth of CRPC in vitro and in vivo [39].
Another coactivator involved in prostate cancer proliferation is Tip60, which promotes AR translocation into the nucleus [40]. Four-and-a-half LIM protein 2 (FHL2) is a coactivator promoting the proliferation of prostate cancer cells. Deregulation of the FHL2-filamin complex promotes constitutive, ligand-independent activation of AR variants such as ARV7 [41]. The expression of nuclear FHL2 in prostatectomy specimens was associated with prostate cancer recurrence [42].

Finally, Hic-5/ARA55 coactivator is expressed in prostate stromal cells and is necessary for androgen induction of the stromal paracrine factor, keratinocyte growth factor [43].

\section{Androgen receptor variants}

It has been known for more than 2 decades that AR has splicing variants [44]. Wild-type full-length AR had the NTD domain encoded by exon 1, DBD encoded by exons 2 and 3, and LBD encoded by exons 4-8 [45]. More than $20 \mathrm{AR}$ variants have been reported, and most are missing some C-terminal domain including LBDs [46,47] (Fig. 1B). The LBD is the target of enzalutamide, and these AR variants are functionally active without androgens. AR-V1 is truncated at the end of exon 3 and contains 19 amino acids from cryptic exon 1. $\mathrm{AR}-\mathrm{V} 7$ is truncated at the end of exon 3 and contains 16 amino acids from cryptic exon 3. AR-V567es has exons 5-7 spliced out and only contains a small portion of the LBD [12]. AR-V1 and AR-V7 were the most abundant variants, with 20-fold higher expression in CRPC compared with hormone-naïve prostate cancer [47]. AR$\mathrm{V} 7$ is located in the nucleus under androgen-depleted conditions and is constitutively active in androgenresponsive genes.

Prostate cancer cell expressing full-length AR and $\mathrm{AR}$ variants are androgen independent and resistant to enzalutamide. However, selective knock-down of AR variants in these cells suppressed androgen-independent growth and restored the responsiveness to enzalutamide [48]. When human CRPC xenografts were treated with abiraterone, the expression of full-length $\mathrm{AR}$ and $\mathrm{AR}$ variants (AR-V567es and AR-V7) were increased in CRPCs. The resistance to abiraterone may occur through the induction of $\mathrm{AR}$ and $\mathrm{AR}$ variants [49]. Expression of AR variants AR-V1 and AR-V7 was increased in CRPC compared with hormone-naïve bone metastases. AR-V567es was detected in CRPC bone metastasis but not in hormone-naïve bone metastasis. 
Expression of AR-V567es and/or AR-V7 was associated with poor survival [50]. Thirty-nine percent of enzalutamide-treated patients and 19\% of abiraterone-treated patients with metastatic CRPC had detectable AR-V7 in their circulating tumor cells. AR-V7-positive patients treated with enzalutamide or abiraterone had a lower PSA response rate and a poorer prognosis than AR-V7negative patients [51]. However, the circulating tumor cells in AR-V7-positive CRPC patients were not resistant to docetaxel or cabazitaxel. In AR-V7-positive men, taxanes were more efficacious than enzalutamide or abiraterone therapy, whereas there were no differences in efficacy between chemotherapy and enzalutamide or abiraterone in AR-V7-negative CRPC patients [52]. ARdirected therapies such as androgen deprivation therapy, enzalutamide, and abiraterone could induce AR-V7 expression in circulating tumor cells, whereas chemotherapy such as docetaxel and cabazitaxel diminished the expression of AR-V7 [53]. These changes of ARV7 in circulating tumor cells may reflect the selective pressures on prostate cancer cells by the treatments. Immunohistochemical detection of AR-V7 in newly diagnosed hormone-naïve prostate cancer was associated with a lower PSA response rate by androgen deprivation therapy and lower overall survival. The detection AR-V7 was also a significant predictor of progression to CRPC in hormone-naïve prostate cancer [54].

\section{NEW ANDROGEN RECEPTOR- TARGETED THERAPIES}

Anti-androgens such as bicalutamide and flutamide bind to the LBD of AR, resulting in the inhibition of androgen binding to LBD. In the progression of prostate cancer to CRPC, prostate cancer survives and resumes its growth under castration levels of androgen by the above-mentioned mechanisms. Enzalutamide is a second-generation nonsteroidal antiandrogen with greater affinity for the LBD of AR [55]. The AFFIRM trials confirmed that enzalutamide significantly prolonged the overall survival of patients with metastatic CRPC after chemotherapy by 4.8 months [56]. CYP17A1 plays key roles in adrenal and intratumoral de novo biosynthesis of androgens, and abiraterone is an inhibitor of CYP17A1 [57]. The COU-AA-301 trial showed that combination therapy of abiraterone acetate with prednisone significantly prolonged overall survival of patients with metastatic CRPC after chemotherapy by 3.7 months [58]. The efficacy of enzalutamide and abiraterone was also confirmed in patients with metastatic CRPC before chemotherapy [59,60]. However, patients with CRPC will eventually gain resistance to enzalutamide or abiraterone. Several new AR-directed drugs are undergoing clinical trials in patients with CRPC.

Apalutamide (ARN-509) is a nonsteroidal antiandrogen with greater efficacy than enzalutamide. Apalutamide binds to the LBD and in contrast to bicalutamide, lacks agonist activity. Apalutamide inhibits nuclear localization and DNA binding of AR in prostate cancer cells [61]. The SPARTAN study showed that metastasis-free survival was significantly lengthened by 24.3 months with apalutamide versus placebo in patients with non-metastatic CRPC [62]. The US Food and Drug Administration approved apalutamide for patients with non-metastatic CRPC in February 2018.

Darolutamide (ODM-201) is a nonsteroidal antiandrogen that inhibits androgen binding to AR. Darolutamide antagonizes both overexpressed and mutated ARs (F876L), which confers resistance to enzalutamide and apalutamide. It can also inhibit AR transcriptional activity with point mutations of F877L, H875Y/T878A, F877L/T878A, and T878G [63]. Darolutamide showed negligible penetrance of the brain-blood barrier [64]. A phase 1 study showed that darolutamide was well tolerated in patients with CRPC [65]. Darolutamide is currently undergoing a phase 3 trial (ARAMIS) in men with high-risk non-metastatic CRPC (NCT02200614).

Galeterone is a new androgen-targeted agent that inhibits CYP17, antagonizes the AR, and reduces AR expression in prostate cancer cells by causing an increase in the degradation of both full-length $\mathrm{AR}$ and ARV7 [66]. Galeterone is also effective for prostate cancer cells with the T878A AR mutation [67]. Open-label phase I and II studies (Androgen Receptor Modulation Optimized for Response-1 [ARMOR1] and ARMOR2 part 1) showed that a more than $30 \%$ decline in PSA was achieved by galeterone in $49 \%$ of patients with treatment-naive non-metastatic or metastatic CRPC [68]. A study of galeterone compared to enzalutamide in men expressing AR-V7 metastatic CRPC (ARMOR3$\mathrm{SV}$ ) is now underway (NCT02438007).

All of these AR-targeted therapies target the LBD. The NTD contains AF-1, which is essential for AR transcriptional activity. EPI-506 is a prodrug of EPI- 
002, which is an antagonist of AF-1. EPI, which effectively inhibits the growth of prostate cancer in vitro and in vivo, has results in aberrant $\mathrm{AR}$ activity, including overexpression of coactivators, $\mathrm{AR}$ gain-of-function mutations, and constitutively active AR-V7 [69]. A phase I/II clinical trial of EPI-506 for patients with metastatic CRPC who are resistant to abiraterone and/ or enzalutamide is now being conducted (NCT02606123).

\section{CONCLUSIONS}

AR plays pivotal roles in prostate cancer, especially in the development of CRPC and the acquisition of resistance to AR-directed therapy. Even after the development of new AR-targeted therapy, CRPC will eventually gain resistance. Understanding the mechanisms of this resistance will enable the development of newgeneration therapies against CRPC.

\section{Disclosure}

The authors have no potential conflicts of interest to disclose.

\section{Author Contribution}

Conceptualization: Nonomura N, Writing (review \& editing): Fujita K.

\section{REFERENCES}

1. Denmeade SR, Isaacs JT. A history of prostate cancer treatment. Nat Rev Cancer 2002;2:389-96.

2. Chang CS, Kokontis J, Liao ST. Molecular cloning of human and rat complementary DNA encoding androgen receptors. Science 1988;240:324-6.

3. Gottlieb B, Beitel LK, Nadarajah A, Paliouras M, Trifiro M. The androgen receptor gene mutations database: 2012 update. Hum Mutat 2012;33:887-94.

4. Beilin J, Ball EM, Favaloro JM, Zajac JD. Effect of the androgen receptor CAG repeat polymorphism on transcriptional activity: specificity in prostate and non-prostate cell lines. J Mol Endocrinol 2000;25:85-96.

5. Giovannucci E, Stampfer MJ, Krithivas K, Brown M, Dahl D, Brufsky A, et al. The CAG repeat within the androgen receptor gene and its relationship to prostate cancer. Proc Natl Acad Sci U S A 1997;94:3320-3.

6. Finsterer J. Bulbar and spinal muscular atrophy (Kennedy's disease): a review. Eur J Neurol 2009;16:556-61.
7. Gelmann EP. Molecular biology of the androgen receptor. J Clin Oncol 2002;20:3001-15.

8. Takayama K, Inoue S. Transcriptional network of androgen receptor in prostate cancer progression. Int J Urol 2013;20: 756-68.

9. Shang Y, Myers M, Brown M. Formation of the androgen receptor transcription complex. Mol Cell 2002;9:601-10.

10. El-Alfy M, Luu-The V, Huang XF, Berger L, Labrie F, Pelletier G. Localization of type 5 17beta-hydroxysteroid dehydrogenase, 3beta-hydroxysteroid dehydrogenase, and androgen receptor in the human prostate by in situ hybridization and immunocytochemistry. Endocrinology 1999;140:1481-91.

11. Lai KP, Yamashita S, Huang CK, Yeh S, Chang C. Loss of stromal androgen receptor leads to suppressed prostate tumourigenesis via modulation of pro-inflammatory cytokines/ chemokines. EMBO Mol Med 2012;4:791-807.

12. Shafi AA, Yen AE, Weigel NL. Androgen receptors in hormone-dependent and castration-resistant prostate cancer. Pharmacol Ther 2013;140:223-38.

13. Tomlins SA, Rhodes DR, Perner S, Dhanasekaran SM, Mehra $\mathrm{R}$, Sun XW, et al. Recurrent fusion of TMPRSS2 and ETS transcription factor genes in prostate cancer. Science 2005; 310:644-8.

14. Robinson D, Van Allen EM, Wu YM, Schultz N, Lonigro RJ, Mosquera JM, et al. Integrative clinical genomics of advanced prostate cancer. Cell 2015;161:1215-28.

15. Waltering KK, Urbanucci A, Visakorpi T. Androgen receptor (AR) aberrations in castration-resistant prostate cancer. Mol Cell Endocrinol 2012;360:38-43.

16. Grasso CS, Wu YM, Robinson DR, Cao X, Dhanasekaran SM, Khan AP, et al. The mutational landscape of lethal castrationresistant prostate cancer. Nature 2012;487:239-43.

17. Taplin ME, Bubley GJ, Shuster TD, Frantz ME, Spooner AE, Ogata GK, et al. Mutation of the androgen-receptor gene in metastatic androgen-independent prostate cancer. N Engl J Med 1995;332:1393-8.

18. Yoshida T, Kinoshita H, Segawa T, Nakamura E, Inoue T, Shimizu Y, et al. Antiandrogen bicalutamide promotes tumor growth in a novel androgen-dependent prostate cancer xenograft model derived from a bicalutamide-treated patient. Cancer Res 2005;65:9611-6.

19. Lallous N, Volik SV, Awrey S, Leblanc E, Tse R, Murillo J, et al. Functional analysis of androgen receptor mutations that confer anti-androgen resistance identified in circulating cell-free DNA from prostate cancer patients. Genome Biol 2016;17:10.

20. Azad AA, Volik SV, Wyatt AW, Haegert A, Le Bihan S, Bell $\mathrm{RH}$, et al. Androgen receptor gene aberrations in circulating cell-free DNA: biomarkers of therapeutic resistance in castra- 
tion-resistant prostate cancer. Clin Cancer Res 2015;21:231524.

21. Joseph JD, Lu N, Qian J, Sensintaffar J, Shao G, Brigham D, et al. A clinically relevant androgen receptor mutation confers resistance to second-generation antiandrogens enzalutamide and ARN-509. Cancer Discov 2013;3:1020-9.

22. Korpal M, Korn JM, Gao X, Rakiec DP, Ruddy DA, Doshi S, et al. An F876L mutation in androgen receptor confers genetic and phenotypic resistance to MDV3100 (enzalutamide). Cancer Discov 2013;3:1030-43.

23. Romanel A, Gasi Tandefelt D, Conteduca V, Jayaram A, Casiraghi $\mathrm{N}$, Wetterskog $\mathrm{D}$, et al. Plasma AR and abirateroneresistant prostate cancer. Sci Transl Med 2015;7:312re10.

24. Goldstein A, Toro PV, Lee J, Silberstein JL, Nakazawa M, Waters I, et al. Detection fidelity of AR mutations in plasma derived cell-free DNA. Oncotarget 2017;8:15651-62.

25. van de Wijngaart DJ, Molier M, Lusher SJ, Hersmus R, Jenster G, Trapman J, et al. Systematic structure-function analysis of androgen receptor Leu701 mutants explains the properties of the prostate cancer mutant L701H. J Biol Chem 2010;285: 5097-105.

26. Visakorpi T, Hyytinen E, Koivisto P, Tanner M, Keinänen $\mathrm{R}$, Palmberg $\mathrm{C}$, et al. In vivo amplification of the androgen receptor gene and progression of human prostate cancer. Nat Genet 1995;9:401-6.

27. LaTulippe E, Satagopan J, Smith A, Scher H, Scardino P, Reuter V, et al. Comprehensive gene expression analysis of prostate cancer reveals distinct transcriptional programs associated with metastatic disease. Cancer Res 2002;62:4499. 506.

28. Chang KH, Li R, Kuri B, Lotan Y, Roehrborn CG, Liu J, et al. A gain-of-function mutation in DHT synthesis in castrationresistant prostate cancer. Cell 2013;154:1074-84.

29. Montgomery RB, Mostaghel EA, Vessella R, Hess DL, Kalhorn TF, Higano CS, et al. Maintenance of intratumoral androgens in metastatic prostate cancer: a mechanism for castration-resistant tumor growth. Cancer Res 2008;68:444754.

30. Cai C, Chen S, Ng P, Bubley GJ, Nelson PS, Mostaghel EA, et al. Intratumoral de novo steroid synthesis activates androgen receptor in castration-resistant prostate cancer and is upregulated by treatment with CYP17A1 inhibitors. Cancer Res 2011;71:6503-13.

31. Szwarc MM, Kommagani R, Lessey BA, Lydon JP. The p160/ steroid receptor coactivator family: potent arbiters of uterine physiology and dysfunction. Biol Reprod 2014;91:122.

32. Agoulnik IU, Vaid A, Bingman WE 3rd, Erdeme H, Frolov A, Smith CL, et al. Role of SRC-1 in the promotion of prostate cancer cell growth and tumor progression. Cancer Res 2005; 65:7959-67.

33. Tien JC, Liu Z, Liao L, Wang F, Xu Y, Wu YL, et al. The steroid receptor coactivator-3 is required for the development of castration-resistant prostate cancer. Cancer Res 2013;73:39974008.

34. Taylor BS, Schultz N, Hieronymus H, Gopalan A, Xiao Y, Carver BS, et al. Integrative genomic profiling of human prostate cancer. Cancer Cell 2010;18:11-22.

35. Qin J, Lee HJ, Wu SP, Lin SC, Lanz RB, Creighton CJ, et al. Androgen deprivation-induced $\mathrm{NCoA} 2$ promotes metastatic and castration-resistant prostate cancer. J Clin Invest 2014; 124:5013-26.

36. Dasgupta S, Putluri N, Long W, Zhang B, Wang J, Kaushik $\mathrm{AK}$, et al. Coactivator SRC-2-dependent metabolic reprogramming mediates prostate cancer survival and metastasis. J Clin Invest 2015;125:1174-88.

37. Geng C, He B, Xu L, Barbieri CE, Eedunuri VK, Chew SA, et al. Prostate cancer-associated mutations in speckle-type $\mathrm{POZ}$ protein (SPOP) regulate steroid receptor coactivator 3 protein turnover. Proc Natl Acad Sci U S A 2013;110:6997-7002.

38. Debes JD, Sebo TJ, Lohse CM, Murphy LM, Haugen DA, Tindall DJ. p300 in prostate cancer proliferation and progression. Cancer Res 2003;63:7638-40.

39. Jin L, Garcia J, Chan E, de la Cruz C, Segal E, Merchant M, et al. Therapeutic targeting of the CBP/p300 bromodomain blocks the growth of castration-resistant prostate cancer. Cancer Res 2017;77:5564-75.

40. Shiota M, Yokomizo A, Masubuchi D, Tada Y, Inokuchi J, Eto M, et al. Tip60 promotes prostate cancer cell proliferation by translocation of androgen receptor into the nucleus. Prostate 2010;70:540-54.

41. McGrath MJ, Binge LC, Sriratana A, Wang H, Robinson PA, Pook D, et al. Regulation of the transcriptional coactivator FHL2 licenses activation of the androgen receptor in castrateresistant prostate cancer. Cancer Res 2013;73:5066-79.

42. Kahl P, Gullotti L, Heukamp LC, Wolf S, Friedrichs N, Vorreuther R, et al. Androgen receptor coactivators lysine-specific histone demethylase 1 and four and a half LIM domain protein 2 predict risk of prostate cancer recurrence. Cancer Res 2006;66:11341-7.

43. Heitzer MD, DeFranco DB. Hic-5/ARA5, a LIM domaincontaining nuclear receptor coactivator expressed in prostate stromal cells. Cancer Res 2006;66:7326-33.

44. Bryce AH, Antonarakis ES. Androgen receptor splice variant 7 in castration-resistant prostate cancer: clinical considerations. Int J Urol 2016;23:646-53.

45. Antonarakis ES, Armstrong AJ, Dehm SM, Luo J. Androgen 
receptor variant-driven prostate cancer: clinical implications and therapeutic targeting. Prostate Cancer Prostatic Dis 2016; 19:231-41.

46. van der Steen T, Tindall DJ, Huang H. Posttranslational modification of the androgen receptor in prostate cancer. Int J Mol Sci 2013;14:14833-59.

47. Hu R, Dunn TA, Wei S, Isharwal S, Veltri RW, Humphreys E, et al. Ligand-independent androgen receptor variants derived from splicing of cryptic exons signify hormone-refractory prostate cancer. Cancer Res 2009;69:16-22.

48. Li Y, Chan SC, Brand LJ, Hwang TH, Silverstein KA, Dehm SM. Androgen receptor splice variants mediate enzalutamide resistance in castration-resistant prostate cancer cell lines. Cancer Res 2013;73:483-9.

49. Mostaghel EA, Marck BT, Plymate SR, Vessella RL, Balk S, Matsumoto AM, et al. Resistance to CYP17A1 inhibition with abiraterone in castration-resistant prostate cancer: induction of steroidogenesis and androgen receptor splice variants. Clin Cancer Res 2011;17:5913-25.

50. Hörnberg E, Ylitalo EB, Crnalic S, Antti H, Stattin P, Widmark A, et al. Expression of androgen receptor splice variants in prostate cancer bone metastases is associated with castration-resistance and short survival. PLoS One 2011;6:e19059.

51. Antonarakis ES, Lu C, Wang H, Luber B, Nakazawa M, Roeser JC, et al. AR-V7 and resistance to enzalutamide and abiraterone in prostate cancer. N Engl J Med 2014;371:1028-38.

52. Antonarakis ES, Lu C, Luber B, Wang H, Chen Y, Nakazawa $\mathrm{M}$, et al. Androgen receptor splice variant 7 and efficacy of taxane chemotherapy in patients with metastatic castrationresistant prostate cancer. JAMA Oncol 2015;1:582-91.

53. Nakazawa M, Lu C, Chen Y, Paller CJ, Carducci MA, Eisenberger MA, et al. Serial blood-based analysis of AR-V7 in men with advanced prostate cancer. Ann Oncol 2015;26:1859-65.

54. Li H, Wang Z, Xiao W, Yan L, Guan W, Hu Z, et al. Androgenreceptor splice variant-7-positive prostate cancer: a novel molecular subtype with markedly worse androgen-deprivation therapy outcomes in newly diagnosed patients. Mod Pathol 2018;31:198-208.

55. Tran C, Ouk S, Clegg NJ, Chen Y, Watson PA, Arora V, et al. Development of a second-generation antiandrogen for treatment of advanced prostate cancer. Science 2009;324:787-90.

56. Scher HI, Fizazi K, Saad F, Taplin ME, Sternberg CN, Miller K, et al. Increased survival with enzalutamide in prostate cancer after chemotherapy. N Engl J Med 2012;367:1187-97.

57. Imamura Y, Sadar MD. Androgen receptor targeted therapies in castration-resistant prostate cancer: bench to clinic. Int J Urol 2016;23:654-65.

58. de Bono JS, Logothetis CJ, Molina A, Fizazi K, North S, Chu L, et al. Abiraterone and increased survival in metastatic prostate cancer. N Engl J Med 2011;364:1995-2005.

59. Ryan CJ, Smith MR, de Bono JS, Molina A, Logothetis CJ, de Souza $\mathrm{P}$, et al. Abiraterone in metastatic prostate cancer without previous chemotherapy. N Engl J Med 2013;368:138-48.

60. Beer TM, Armstrong AJ, Rathkopf DE, Loriot Y, Sternberg $\mathrm{CN}$, Higano CS, et al. Enzalutamide in metastatic prostate cancer before chemotherapy. N Engl J Med 2014;371:424-33.

61. Clegg NJ, Wongvipat J, Joseph JD, Tran C, Ouk S, Dilhas A, et al. ARN-509: a novel antiandrogen for prostate cancer treatment. Cancer Res 2012;72:1494-503.

62. Smith MR, Saad F, Chowdhury S, Oudard S, Hadaschik BA, Graff JN, et al. Apalutamide treatment and metastasis-free survival in prostate cancer. N Engl J Med 2018;378:1408-18.

63. Borgmann H, Lallous N, Ozistanbullu D, Beraldi E, Paul N, Dalal K, et al. Moving towards precision urologic oncology: targeting enzalutamide-resistant prostate cancer and mutated forms of the androgen receptor using the novel inhibitor darolutamide (ODM-201). Eur Urol 2018;73:4-8.

64. Moilanen AM, Riikonen R, Oksala R, Ravanti L, Aho E, Wohlfahrt G, et al. Discovery of ODM-201, a new-generation androgen receptor inhibitor targeting resistance mechanisms to androgen signaling-directed prostate cancer therapies. Sci Rep 2015;5:12007.

65. Matsubara N, Mukai H, Hosono A, Onomura M, Sasaki M, Yajima Y, et al. Phase 1 study of darolutamide (ODM-201): a new-generation androgen receptor antagonist, in Japanese patients with metastatic castration-resistant prostate cancer. Cancer Chemother Pharmacol 2017;80:1063-72.

66. Kwegyir-Afful AK, Ramalingam S, Purushottamachar P, Ramamurthy VP, Njar VC. Galeterone and VNPT55 induce proteasomal degradation of AR/AR-V7, induce significant apoptosis via cytochrome $\mathrm{c}$ release and suppress growth of castration resistant prostate cancer xenografts in vivo. Oncotarget 2015;6:27440-60.

67. Yu Z, Cai C, Gao S, Simon NI, Shen HC, Balk SP. Galeterone prevents androgen receptor binding to chromatin and enhances degradation of mutant androgen receptor. Clin Cancer Res 2014;20:4075-85.

68. Montgomery B, Eisenberger MA, Rettig MB, Chu F, Pili R, Stephenson JJ, et al. Androgen receptor modulation optimized for response (ARMOR) phase I and II studies: galeterone for the treatment of castration-resistant prostate cancer. Clin Cancer Res 2016;22:1356-63.

69. Yang YC, Banuelos CA, Mawji NR, Wang J, Kato M, Haile $S$, et al. Targeting androgen receptor activation function-1 with EPI to overcome resistance mechanisms in castrationresistant prostate cancer. Clin Cancer Res 2016;22:4466-77. 